\title{
It's (Not) in The Reading: American Government Textbooks' Limited Representation of Historically Marginalized Groups
}

Shawna M. Brandle, Kingsborough Community College

ABSTRACT The Introduction to American Government course, and its textbook, is a nearly universal experience for students in American colleges and universities, but what exactly is being taught in this course? Do the textbooks used in this widely taught course accurately reflect the diversity of populations and experiences in the United States? More specifically, how do textbooks for Introduction to American Government cover historically marginalized groups, if at all? This article builds on previous work by analyzing the representation of individual historically marginalized groups to conduct index search and content analyses on traditionally published and openly licensed (i.e., open educational resources [OER]) textbooks. This study finds that American government textbooks include little coverage of any historically marginalized groups, and that OER textbooks are average in this respect, doing neither better nor worse than their traditionally published counterparts.

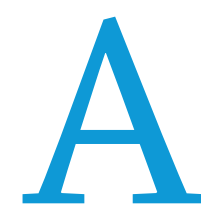

lthough it is a foundational course in political science, the content of Introduction to American Government is seldom studied within the discipline. Nevertheless, it is important to look at the the textbooks because they are the first science, and they repre in American government (Atchison 2017). Do the materials used in these courses reflect the diversity of populations and experiences in the United States? ? $^{1}$

\section{ANALYSES OF REPRESENTATIONS OF HISTORICALLY MARGINALIZED GROUPS IN POLITICAL SCIENCE}

The limited representation of historically marginalized groups has been examined across several subfields of political science. Tolley (2020) analyzed five popular introductory textbooks on Canadian government and found limited coverage of immigrants and

Shawna M. Brandle (D) is associate professor of history, philosophy, and political science at Kingsborough Community College. She can be reached at shawna.brandle@kbcc.cuny.edu. minorities. Looking at 10 general introduction to political science textbooks, Atchison (2017) found a similar lack of coverage of women, indicating a systematic problem across the discipline, not only in American government textbooks. A comprehensive review (Knutson 2017, 536) of five American government textbooks, aimed at assisting instructors "who value different approaches" to select texts for course adoption, did not include coverage of historically marginalized groups as reviewing criteria, implying that it is not something Knutson (2017) believes instructors would be interested in when deciding on a textbook. In this, Knutson was following the general approach of the discipline of political science, as highlighted by Strach $(2019,12)$, who summarized how these issues are marginalized: "Political scientists consider such work to be about race and politics, or sexuality and politics, or gender and politics, not politics."

Several studies analyze American government textbooks for representation of different races and ethnicities, as well as women and LGBTQ persons, establishing a baseline for representation in American government textbooks. Ashley and Jarrat-Ziemski $(1999,59)$ used an index keyword search to compare the amount

(C) The Author(s), 2020. Published by Cambridge University Press on behalf of American Political Science Association. This is an Open Access article, distributed under the terms of the Creative Commons Attribution-NonCommercial-Share Alike licence (http://creativecommons.org/licenses/by-nc-sa/4.o/), which permits non-commercial re-use, distribution, and reproduction in any medium, provided the same Creative Commons licence is included and the original work is properly cited. The written permission of 
of coverage of Native Americans to other minority groups, finding "that American government texts do a generally abysmal job when it comes to adequately dealing with Native Americans." Novkov and Gossett (2007, 393) examined LGBTQ representation in 17 American government textbooks; they found that all of the texts included references to lesbians and gay men "almost universally in discussions of civil rights and/or equality," bisexuals were rarely included, and transgender individuals were completely absent.

Modeling on Novkov and Gossett (2007), Wallace and Allen (2008) found that African Americans are the most represented of any racial/ethnic groups, but that most of the reviewed textbooks ignore the contributions of African Americans to American political development until the civil rights movement-even then, representations of this involvement are siloed in standalone sections or chapters on civil rights. Using Wallace and Allen (2008) and Novkov and Gossett (2007) as models, Monforti and McGlynn (2010) examined Latinx representation. Their findings concur with Wallace and Allen's (2008), in both the limited amount of coverage and the exiling of that coverage to civil rights chapters. Takeda (2015) used an index-search-based approach on the most recent editions of the textbooks in Monforti and McGlynn (2010) for coverage of Asian American/Pacific Islanders and found that an extremely small number of pages included coverage of this group.

With regard to gender representation in American government textbooks, Olivo (2012) and Cassese, Bos, and Schneider (2014) came to a similar conclusion as the authors who studied race and ethnicity: "[c]ontent about women is scarce, marginalized, and stereotypical" Cassese, Bos, and Schneider (2014, 254).

Taken together, these studies indicate that coverage of historically marginalized groups is extremely limited in American government textbooks. By combining the search terms from these studies into one study, I provide a comprehensive view of representation (or lack thereof) of historically marginalized groups in American government textbooks.

\section{TEXTBOOK COST AND OPEN EDUCATIONAL RESOURCES}

It is impossible to discuss textbooks without discussing their exponentially rising cost. Textbook costs have been steadily rising since the late 1990s, averaging a 6\% increase per year through 2016 (Perry 2019). The high cost of textbooks has been linked to negative student outcomes, such as not purchasing required textbooks, earning poor grades, and dropping courses ("2018 Student Textbook and Course Materials Survey" 2019, 3). One response to the increasing costs of textbooks has been the creation and adoption of open educational resources (OER). OER are "teaching, learning, and research materials in any medium, digital or otherwise, that reside in the public domain or have been released under an open license that permits no-cost access, use, adaptation, and redistribution by others with no or limited restrictions" (Paris OER Declaration 2012). Although OER have been in use for nearly two decades (Cronin 2018) and their efficacy has been studied in several courses from various institutions and perspectives, ${ }^{2}$ they are even less studied than textbooks by the journals published by the American Political Science Association. There are two OER articles in Journal of Political Science Education, one of which I wrote, and none in the other three journals.

\section{CULTURALLY RESPONSIVE TEACHING AND OER}

There is significant research that establishes the need for culturally responsive teaching in primary and secondary education. Ladson-Billings (2009) demonstrated that teaching that ignores African American students' culture is teaching that significantly decreases those students' chances for academic success. Gay (2000) demonstrated how students of color are continually shortchanged by pedagogies, curricula, and textbooks that ignore their cultures and identities. She called for culturally responsive teaching, including revising and supplementing teaching materials and textbooks, to improve educational outcomes for students of color. Larke $(2018,38)$ argued that culturally responsive teaching practices should be adopted by instructors of higher education because it leads to more equitable outcomes for all students, especially as higher-education student bodies become "more and more culturally, linguistically, economically, and ethnically diverse." Because their low costs make them accessible to all students regardless of their income, and because they are licensed for revision and remixing, OER have the potential to address both equity and inclusion concerns. It is important to note, however, that OER are not necessarily automatically more culturally responsive.

\section{HYPOTHESIS}

I expect that current American government textbooks will have extremely limited coverage of historically marginalized groups whereas OER textbooks will have more and better coverage of historically marginalized groups (operationalized as African Americans, Latino/a Americans, Asian Americans, Native Americans, women, and LGBTQ persons) than their traditionally published counterparts for several reasons. Previous studies of representations of historically marginalized groups in American government textbooks reveal little coverage of these groups, making it likely that current traditionally published books will continue that trend, thereby making it a low threshold for OER books to exceed. Additionally, the content in OER textbooks has been developed more recently rather than being revised editions of materials that are a decade or more older. Finally, OER textbooks are part of the open education movement, which seeks to address more than just the inequality-of-access issues due to the rising costs of textbooks. A major benefit touted by OER advocates is the ability to produce more up-to-date, representative, and culturally responsive materials.

\section{METHODOLOGY}

To explore whether and how introductory American government textbooks cover historically marginalized groups, I adapted the methods of previous studies, conducting both an index search and a full-text content analysis. To obtain a wide variety of texts, I used three different means to select traditionally published textbooks for the index search. I selected four of the most recent editions of the previous studies' highest ranked textbooks, three textbooks used in American government syllabi in APSA's syllabus bank, and three textbooks from Amazon's Top 100 government textbooks list, as well as one OER textbook. ${ }^{3}$ I conducted an index search using a list of terms combined from the articles covering individual historically marginalized groups, to which I added three additional search terms for essential US Supreme Court decisions that relate to LGBTQ rights that did not exist at the time of the Novkov and Gossett (2007) paper: United States vs. Windsor, Hollingsworth vs. Perry, and Obergefell vs. Hodges. This resulted 
in a search list of 205 unique terms,${ }^{4}$ which then were coded according to which historically marginalized group the term referred: General (23 words, for terms that were not obviously applicable to a single group); African American (6); African American and Women (2); Asian American/Pacific Islander (27); Latinx (47); Latinx and Native American (1); Latinx and Women (4); Native American (3); LGBTQ (18); and Women (74). Individual listing pages were counted for each entry on the list. ${ }^{5}$

I also conducted a content analysis of entire texts by collecting PDF files of 13 textbooks for analysis in Wordstat: four free digital marginalized groups is not evenly distributed. General search words that were not specific to any one marginalized group were the most indexed; words related to women came in second. The highest number of indexed pages in each book was largely from the General category, with other groups receiving much less coverage in every book and little coverage overall.

The total number of indexed pages is somewhat deceptive because 3,544 reflects numerous duplicate pages; that is, the same textbook page might be indexed for several different search words. Table 1 shows the number of deduplicated pages that had at least

\section{All but one of the 11 textbooks siloed more than 20\% of their inclusion of historically marginalized groups into chapters on civil rights...}

textbooks ${ }^{6}$ and nine traditionally published textbooks. A categorization dictionary derived from the index search words was created to see how frequently each historically marginalized group was mentioned throughout the textbooks.?

\section{INDEX SEARCH RESULTS}

Across the 11 textbooks analyzed, 3,544 pages were found in the indices for 131 search terms. This is a small number compared to the total 5,735 non-index and non-appendix pages of all 11 books. ${ }^{8}$ Not only were few pages indexed, but also only $61 \%$ of the 205 search terms (131) had at least one page indexed in at least one book; this means that one third of the search words were not present in the indices of any of the 11 books analyzed. Fifteen search words were indexed on only one page in one book. Only 65 search words were indexed on 10 or more pages across the 11 books analyzed, and only five search words were indexed in all 11 books: Voting Rights Act, Roe vs. Wade, affirmative action, Elena Kagan, and the Defense of Marriage Act. Limited representation of most marginalized groups was consistent across all textbooks reviewed, with McClain and Tauber (2018) as a noticeable outlier (figure 1). The average number of search-word pages per book was 322, with seven of the 11 books less than the average. Figure 1 also shows that the representation of different historically one search word on a page. When the 2,001 duplicate pages were removed, only 1,543 unique pages across all 11 books had at least one search word, representing $26.9 \%$ of the substantive pages in all 11 books. The textbooks varied widely in the percentage of pages that had at least one indexed search word. The Openstax book scored lowest with $10 \%$, whereas the McClain and Tauber (2018) percentage of $60.5 \%$ is almost twice the next highest percentage from Welch et al. (2014), which is still far above the average.

\section{TEXTBOOKS ANALYZED}

The following is the list of textbooks analyzed:
1. Krutz et al. 2019
2. Welch et al. 2014
3. Gaddie and Dye 2018
4. O'Connor and Sabato 2018
5. Schmidt, Shelley, and Bardes 2018
6. Barbour and Wright 2015
7. Ginsberg et al. 2017
8. Kollman 2015
9. McClain and Tauber 2018
10. Morone and Kersh 2018
11. Patterson 2015

\section{Figure 1}

Distribution of Index Pages Found for Each Historically Marginalized Group 1000

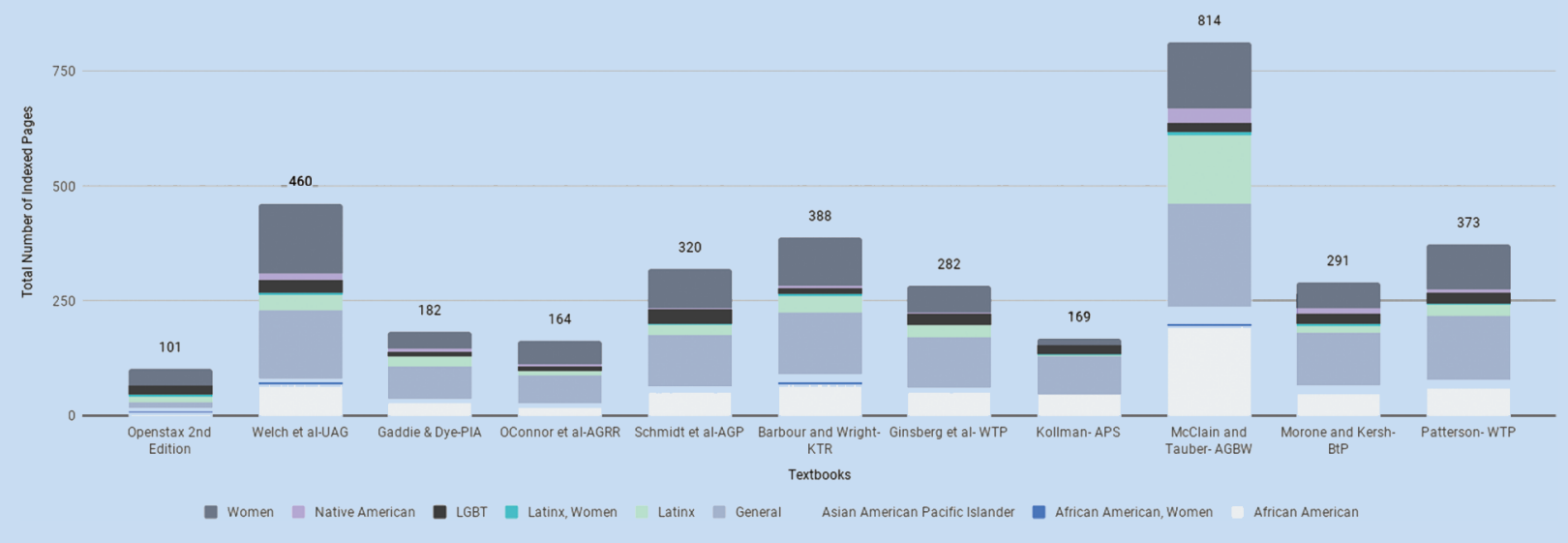


The frequency of search words occurring on the same pages indicates a clustering of representation of historically marginalized groups rather than these groups being included throughout the text. Tolley (2020) found that Canadian political science textbooks often
Based on the index analysis, it appears that American government textbooks do not devote much coverage to historically marginalized groups. The book with by far the highest number of indexed pages, the most deduplicated pages, and the lowest

\section{Across all books, words referring to historically marginalized groups came up rarely: of $3,741,902$ total words, only 31,340 , or $0.84 \%$, were in the categorization dictionary.}

silo their representations of immigrants and minorities in diversityspecific chapters, presenting oppression of these groups as historical artefacts, not contemporary issues. Novkov and Gossett (2007), Wallace and Allen (2008), Takeda (2015), and Monforti and McGlinn (2010) found similar ghettoization. To test whether this percentage of siloed pages was McLain and Tauber's (2018) American Government in Black and White: Diversity and Democracy. This is perhaps unsurprising because it also is the only book with an explicit focus on racial and ethnic equality as a framing principle. The OER textbook is not more representative than its

\section{By also rather seldomly using words about historically marginalized groups, OER fit right in with the bulk of their traditionally published American government peers.}

is still the case in American government textbooks, deduplicated pages were coded for the chapter in which they appeared in each book and whether that chapter was the civil rights chapter. All but one of the 11 textbooks siloed more than $20 \%$ of their inclusion of historically marginalized groups into chapters on civil rights (see table 1). The average across all books was $26.8 \%$ of indexed mentions of historically marginalized groups that were siloed in civil rights chapters. Moreover, 18 chapters across six books did not contain a single indexed reference to a historically marginalized group. traditionally published counterparts, scoring low on most counts of the index analysis.

But is the index analysis alone a sufficient measure of representation of historically measured groups? The Openstax index is shorter than its traditionally published counterparts, which could explain some of the reason that it scores so far behind them. Index searching is subject to specific word order, which might leave some pages undercounted. Finally, as more students access digital versions of their textbooks,

\section{Figure 2}

\section{Historically Marginalized Group Word Frequencies in 13 American Government Textbooks}

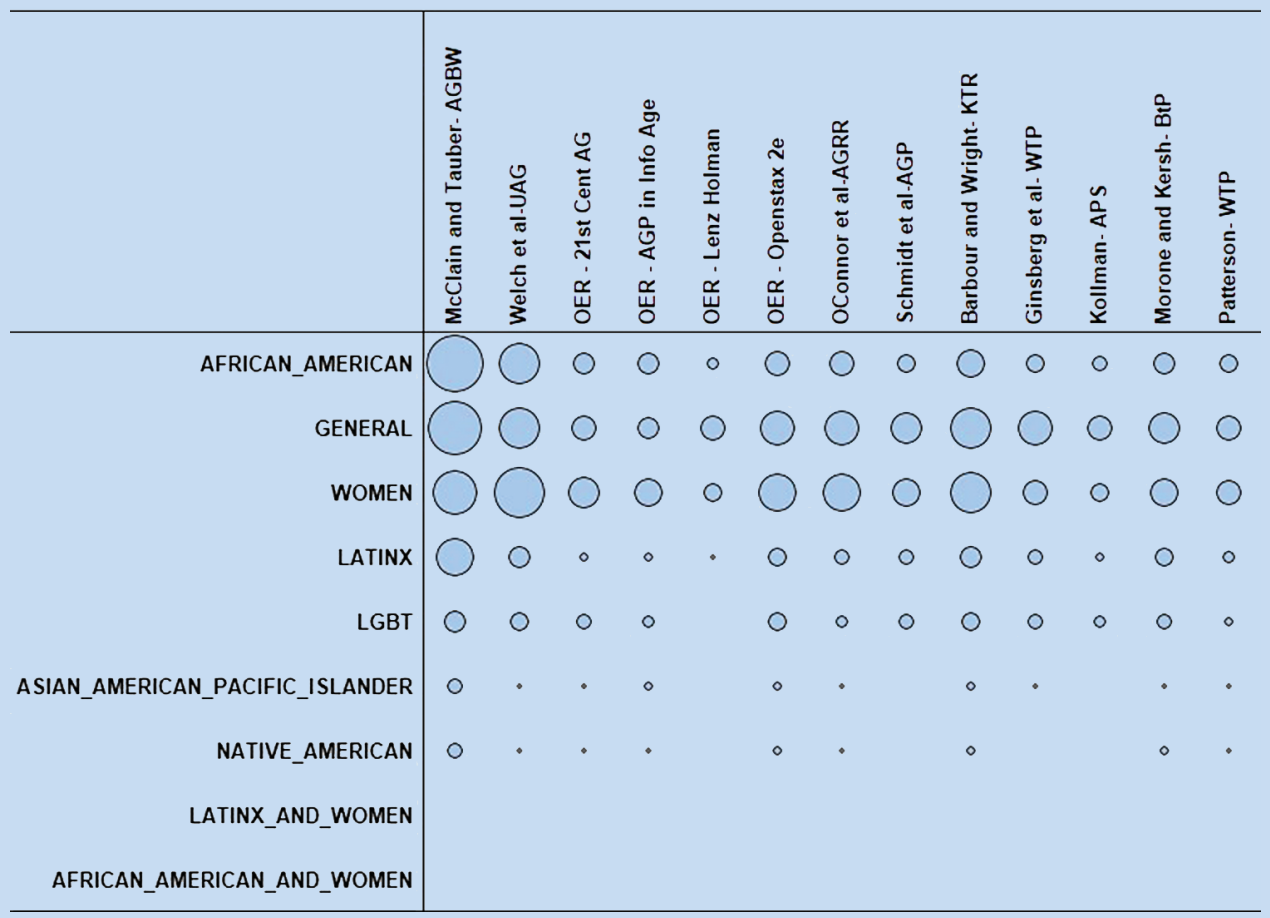


Table 1

Indexed Search Words, Deduplicated Pages, and Pages in Civil Rights Chapters in 11 American Government Textbooks

\begin{tabular}{|c|c|c|c|c|c|c|c|c|c|c|c|}
\hline & 1 & 2 & 3 & 4 & 5 & 6 & 7 & 8 & 9 & 10 & 11 \\
\hline $\begin{array}{l}\text { Total Number of Pages with a } \\
\text { Search Word from Any Study* }\end{array}$ & 101 & 460 & 182 & 164 & 320 & 388 & 282 & 169 & 814 & 291 & 373 \\
\hline $\begin{array}{l}\text { Deduplicated Number of Pages } \\
\text { with a Search Word }\end{array}$ & 68 & 176 & 106 & 95 & 123 & 167 & 117 & 92 & 328 & 145 & 126 \\
\hline \# of Index Pages & 13 & 26 & 15 & 21 & 33 & 15 & 31 & 17 & 27 & 23 & 31 \\
\hline $\begin{array}{l}\text { \# of Pages (Excluding } \\
\text { Appendices, Index, and } \\
\text { Reference Section) }\end{array}$ & 658 & 502 & 603 & 413 & 464 & 498 & 463 & 513 & 542 & 507 & 572 \\
\hline $\begin{array}{l}\text { Percentage of Pages with any } \\
\text { Indexed Search Word } \\
\text { [Deduplicated] }\end{array}$ & $10.3 \%$ & $35.1 \%$ & $17.6 \%$ & $23.0 \%$ & $26.5 \%$ & $33.5 \%$ & $25.3 \%$ & $17.9 \%$ & $60.5 \%$ & $28.6 \%$ & $22.0 \%$ \\
\hline $\begin{array}{l}\text { \# of Deduplicated Pages in Civil } \\
\text { Rights Chapter }\end{array}$ & 19 & 41 & 33 & 27 & 30 & 47 & 25 & 31 & 62 & 42 & 36 \\
\hline $\begin{array}{l}\text { \# of Deduplicated Pages in } \\
\text { Other Chapters }\end{array}$ & 49 & 135 & 73 & 68 & 93 & 120 & 92 & 61 & 266 & 103 & 90 \\
\hline $\begin{array}{l}\text { Percentage of HMG Pages } \\
\text { Siloed in Civil Rights Chapter }\end{array}$ & $27.9 \%$ & $23.3 \%$ & $31.1 \%$ & $28.4 \%$ & $24.4 \%$ & $28.1 \%$ & $21.4 \%$ & $33.7 \%$ & $18.9 \%$ & $29.0 \%$ & $28.6 \%$ \\
\hline
\end{tabular}

readers are less likely to use the index at all. It is therefore necessary to examine the content of the textbooks to accurately determine the coverage that historically marginalized groups receive.

\section{FULL-TEXT ANALYSIS RESULTS}

Across all books, words referring to historically marginalized groups came up rarely: of $3,741,902$ total words, only 31,340 , or $0.84 \%$, were in the categorization dictionary. Moreover, only $7.2 \%$ of sentences and $8.9 \%$ of paragraphs included at least one word from the categorization dictionary. Differences in length might explain the variation in the textbooks' use of words; however, when frequency of categorized words per 10,00o words was calculated, none of the textbooks mentioned words related to historically marginalized groups all that frequently (table 2). The infrequent use of these words across all of the textbooks analyzed here indicates that political science as a discipline does not consistently consider these words essential to the study of American government. Again, McClain and Tauber (2018) and Welch et al. (2014) come in first for having used the most categorized words and having the highest rate of categorized words, with the remaining textbooks significantly farther behind. The OER textbooks were neither the highest nor the lowest ranked, meaning that they were neither much better nor much worse than the average of American government textbooks. By also rather seldomly using words about historically marginalized groups, OER fit right in with the bulk of their traditionally published American government peers.

Similar to the index results, word use was not evenly distributed across historically marginalized groups: words from the General and Women categories received the largest amount of coverage, followed by African American words.

\section{CONCLUSION}

It is clear that the American government textbooks studied herein have rather little coverage of historically marginalized groups, whether analyzing indices or in-text frequency. It also is clear that not all groups receive the same amount of coverage, with General terms and Women receiving far more coverage than African Americans, who are covered more than Latinx Americans, LGBTQ Americans, and Asian American/Pacific Islanders.

The reduction of profit motivation is one reason to believe that OER textbooks might handle representation of historically marginalized groups better than their traditionally published counterparts. Yet, based on this analysis, OER textbooks do not perform any better (or any worse) than their traditionally published counterparts when it comes to representation of historically marginalized groups. Elimination of the profit motivation is not sufficient to ensure coverage of historically marginalized groups in American government textbooks.

OER textbooks may have an advantage in their open licensing; that is, instructors are free to revise and republish their own version of openly licensed textbooks. Instructors often supplement textbooks in their courses with articles or summaries, but they are not permitted to rewrite and reissue the text, which limits their ability to share their corrections. OER materials officially permit and often encourage these revisions for faculty who want to make them. In fact, Openstax recently announced that it will be releasing Google Doc versions of all of its textbooks, which will make editing their books even easier (Williamson 2020).

Similar scores among so many different textbooks, both OER and traditionally published, indicates a broad consensus in the way historically marginalized groups are covered in introductory American government textbooks: in a very limited way. The outlier, the McClain and Tauber (2018) textbook, is much more inclusive of historically marginalized groups only because it explicitly intends to be so. Lacking that special intention, the other 12 textbooks examined here default to limited inclusion of historically marginalized groups.

Further research is called for on this topic. Examining the images that textbooks use, as Clawson and Kegler (2000) did, is 
Table 2

Number of Historically Marginalized Group Words and Rate of Categorized Words per 10,000 Words in 13 American Government Textbooks

\begin{tabular}{|c|c|c|}
\hline Textbook & $\begin{array}{c}\text { Number of } \\
\text { Categorized Words }\end{array}$ & $\begin{array}{l}\text { Rate of Categorized } \\
\text { Words } / 10,000\end{array}$ \\
\hline $\begin{array}{l}\text { McClain and } \\
\text { Tauber-AGBW }\end{array}$ & 7,094 & 233.0 \\
\hline Welch et al.-UAG & 4,311 & 97.7 \\
\hline $\begin{array}{l}\text { OER-21st Century } \\
\text { AG }\end{array}$ & 1,643 & 64.4 \\
\hline $\begin{array}{l}\text { OER-AGP in Info } \\
\text { Age }\end{array}$ & 1,518 & 61.1 \\
\hline OER-Lenz Holman & 715 & 38.6 \\
\hline OER-Openstax 2e & 2,554 & 75.0 \\
\hline $\begin{array}{l}\text { O'Connor et al.- } \\
\text { AGRR }\end{array}$ & 2,440 & 72.1 \\
\hline Schmidt et al.-AGP & 1,733 & 76.3 \\
\hline $\begin{array}{l}\text { Barbour and } \\
\text { Wright-KTR }\end{array}$ & 3,328 & 76.2 \\
\hline $\begin{array}{l}\text { Ginsberg et al.- } \\
\text { WTP }\end{array}$ & 1,702 & 71.4 \\
\hline Kollman-APS & 912 & 40.5 \\
\hline $\begin{array}{l}\text { Morone and Kersh- } \\
\text { BtP }\end{array}$ & 2,086 & 83.0 \\
\hline Patterson-WTP & 1,304 & 52.1 \\
\hline
\end{tabular}

\section{Abbreviations Used for Textbooks:}

McClain and Tauber-AGBW: McClain and Tauber 2018

Welch et al.-UAG: Welch et al. 2012

OER-21st Century AG: 21st Century in American Government 2012

OER-AGP in Info Age: American Government and Politics in the Information Age 2016 OER-Lenz Holman: Lenz and Holman 2013

OER-Openstax 2e: Krutz et al. 2019

O'Connor et al.-AGRR: O'Connor, Sabato, and Yanus 2016

Schmidt et al.-AGP: Schmidt, Shelley, and Bardes 2018

Barbour and Wright-KTR: Barbour and Wright 2015

Ginsberg et al.-WTP: Ginsberg et al. 2017

Kollman-APS: Kollman 2015

Morone and Kersh-BtP: Morone and Kersh 2018

Patterson-WTP: Patterson 2015

a fruitful direction because the visual component of textbooks is essential to students' experience of their learning materials. Examination of representations of other marginalized populations, such as people with disabilities or members of religious minority groups, is also warranted, although it fell outside the scope of this project. Finally, in the process of doing this research, it became evident just how much these 205 search terms themselves exclude. More detailed studies that begin with the contents of textbooks and their indexes instead of a list of search terms would be fascinating to see.

\section{SUPPLEMENTARY MATERIALS}

To view supplementary material for this article, please visit http:// dx.doi.org/10.1017/S1049096520000797. -

\section{NOTES}

1. The author gratefully acknowledges the OER Research Fellowship for supporting this research and Boran Beric for his invaluable assistance in procuring files for content analysis.
2. For analysis of OER from students' perspectives, see Brandle et al. (2019) and Jaggars, Folk, and Mullins (2018). For analysis of faculty opinions of OER, see Allen and Seaman (2014). Bliss et al. (2013) covered both faculty and student opinions about OER. For OER effects measured as course completion rates and course grades, see Fischer et al. (2015) and Colvard, Watson, and Park (2018).

3. Further information on textbook selection is in the online appendix.

4. Because 11 terms appeared in the wordlists for two or more articles, I decided to group terms by the historically marginalized group to which they referred instead of the original study in which they occurred. The complete word list, HMG codes, and number of indexed pages for each search term in each book are available in the online appendix.

5. When sublistings were included under a main search list term but were not on the main search list, their indexed pages counted under the main heading. Duplicate pages, such as those due to repetition of pages for sublistings under a main search, were counted only once for each search word. Page ranges were disaggregated to count as individual pages.

6. All free digital textbooks in the full-text analysis initially were considered for the index-search analysis. Only one had an index, however, which is why there is only one OER text in the first analysis and four in the second.

7. The categorization dictionary is available in the online appendix.

8. See table 1 and the following discussion for how 3,544 is an overstatement of the number of pages with representations of historically marginalized groups

\section{REFERENCES}

"2018 Student Textbook and Course Materials Survey." 2019. Available at www.openaccesstextbooks.org/pdf/2016_Florida_Student_Textbook_Survey.pdf.

21st Century American Government and Politics (v. 1.o). 2012. Available at https://2012books.lardbucket.org/pdfs/21st-century-american-government-andpolitics.pdf.

Allen, I. Elaine, and Jeff Seaman. 2014. "Opening the Curriculum: Open Educational Resources in U.S. Higher Education.” Available at http://files.eric.ed.gov/fulltext/ ED572730.pdf.

American Government and Politics in the Information Age. 2016. Available at https:// open.lib.umn.edu/americangovernment.

Ashley, Jeffrey S., and Karen Jarratt-Ziemski. 1999. "Superficiality and Bias: The (Mis)Treatment of Native Americans in U.S. Government Textbooks." American Indian Quarterly 23 (3/4): 49-62. Available at www.jstor.org/stable/1185828.

Atchison, Amy L. 2017. "Where Are the Women? An Analysis of Gender Mainstreaming in Introductory Political Science Textbooks." Journal of Political Science Education 13 (2): 185-99.

Barbour, Christine, and Gerald C. Wright. 2015. Keeping the Republic: Power and Citizenship in American Politics (The Essent). Los Angeles: SAGE Publications.

Bliss, T. J., T. Jared Robinson, John Hilton, and David A. Wiley. 2013. “An OER COUP: College Teacher and Student Perceptions of Open Educational Resources." Journal of Interactive Media in Education 1:4.

Brandle, Shawna, Stacy Katz, Anne Hays, Amy Beth, Cailean Cooney, Jacqueline DiSanto, Linda Miles, and Abigail Morrison. 2019. "But What Do the Students Think: Results of the CUNY Cross-Campus Zero-Textbook Cost Student Survey." Open Praxis 11 (1): 85.

Cassese, Erin C., Angela L. Bos, and Monica C. Schneider. 2014. "Whose American Government? A Quantitative Analysis of Gender and Authorship in American Politics Texts." Journal of Political Science Education 10 (3): 253-72.

Clawson, Rosaelee A., Elizabeth R. Kegler. 200o. "The 'Race Coding' of Poverty in American Government College Textbooks." Howard Journal of Communications 11 (3): 179-88.

Colvard, Nicholas B., Camilla E. Watson, and Hiyojin Park. 2018. "The Impact of Open Educational Resources on Various Student Success Metrics." International Journal of Teaching and Learning in Higher Education 30 (2): 262-75.

Cronin, Catherine. 2018. "Openness and Praxis: A Situated Study of Academic Staff Meaning-Making and Decision-Making with Respect to Openness and Use of Open Educational Practices in Higher Education." Galway: National University of Ireland. Available at https://aran.library.nuigalway.ie/handle/10379/7276.

Fischer, Lane, John Hilton, T. Jared Robinson, and David A. Wiley. 2015. "A MultiInstitutional Study of the Impact of Open Textbook Adoption on the Learning Outcomes of Post-Secondary Students." Journal of Computing in Higher Education 27 (3): 159-72.

Gaddie, Ronald Keith, and Thomas R. Dye. 2018. Politics in America. 2016 Presidential Election Edition. New York: Pearson Higher Education.

Gay, Geneva. 200o. Culturally Responsive Teaching: Theory, Research, and Practice. Multicultural Education Series. New York: Teachers College Press.

Ginsberg, Benjamin, Theodore J. Lowi, Margaret Weir, Catherine J. Tolbert, and Robert J. Spitzer. 2017. We the People: An Introduction to American Politics, 11th edition. New York: W.W. Norton \& Company. 
Jaggars, Shanna S., Amanda Folk, and David Mullins. 2018. "Understanding Students' Satisfaction with OERs as Course Materials." Performance Measurement and Metrics 19 (1): 66-74.

Knutson, Katherine. 2017. "US Government Textbook Review.” PS: Political Science $\mathcal{E}$ Politics 50 (2): 536-41.

Kollman, Ken. 2015. The American Political System (Core Second Edition). New York: W.W. Norton \& Company.

Krutz, Glen, et al. 2019. American Government 2e. Houston, TX: Open Textbook Library.

Ladson-Billings, Gloria. 2009. The Dreamkeepers: Successful Teachers of African American Children. New York: John Wiley \& Sons, Inc.

Larke, Patricia. 2018. "Culturally Responsive Teaching in Higher Education: What Professors Need to Know." The Liberal Arts to the Sciences (2013) 391:38-50.

Lenz, Timothy O., and Mirya Holman. 2013. "American Government.” Available at www.theorangegrove.org.

McClain, Paula, and Steven Tauber. 2018. American Government in Black and White: Diversity and Democracy, third edition. New York: Oxford University Press.

Monforti, Jessica L., and Adam McGlynn. 2010. "Aquí Estamos? A Survey of Latino Portrayal in Introductory U.S. Government and Politics Textbooks." PS: Political Science \& Politics 43 (2): 309-16.

Morone, James, and Rogen Kersh. 2018. By the People: Debating American Government, third edition. New York: Oxford University Press.

Novkov, Julie, and Charles Gossett. 2007. "Survey of Textbooks for Teaching Introduction to U.S. Politics: (How) Do They See Us?" PS: Political Science $\mathcal{E}$ Politics 40 (2): 393-98.

O'Connor, Karen, and Larry Sabato. 2018. American Government: Roots and Reform. Hoboken, NJ: Pearson Higher Education.

O'Connor, Karen, Larry Sabato, and Alixandra B. Yanus. 2016. American Government Roots and Reform, 12th edition. New York: Pearson Higher Education.
Olivo, Christiane. 2012. "Bringing Women In: Gender and American Government and Politics Textbooks." Journal of Political Science Education 8 (2): 131-46.

Paris OER Declaration. 2012. UNESCO. Available at www.unesco.org/new/ fileadmin/MULTIMEDIA/HQ/CI/CI/pdf/Events/English_Paris_OER_ Declaration.pdf.

Patterson, Thomas E. 2015. We the People: An Introduction to American Government, 11th edition. New York: McGraw Hill Education.

Perry, Mark J. 2019. “Chart of the Day...or Century?” Available at www.aei.org/ publication/chart-of-the-day-or-century-2.

Schmidt, Steffen W., Mack C. Shelley, and Barbara A. Bardes. 2018. American Government and Politics Today: The Essentials. Boston: Cengage Learning.

Strach, Patricia. 2019. "What's Wrong with Us? Sexual Misconduct and the Discipline of Political Science." Journal of Women, Politics and Policy 40 (1): 7-20.

Takeda, Okiyoshi. 2015. "A Forgotten Minority? A Content Analysis of Asian Pacific Americans in Introductory American Government Textbooks.” PS: Political Science \& Politics 48 (3): 430-39.

Tolley, Erin. 2020. "Hidden in Plain Sight: The Representation of Immigrants and Minorities in Political Science Textbooks." International Journal of Canadian Studies.

Wallace, Sherri L., and Marcus D. Allen. 2008. "Survey of African American Portrayal in Introductory Textbooks in American Government/Politics: A Report of the APSA Standing Committee on the Status of Blacks in the Profession." PS: Political Science \& Politics 41 (1): 153-6o.

Welch, Susan, John Gruhl, Susan Rigdon, and Sue Thomas. 2012. Understanding American Government, 13th edition. Boston: Wadsworth.

Welch, Susan, John Gruhl, Sue Thomas, and MaryAnne Borrelli. 2014. Understanding American Government, 14th edition. Boston: Cengage Learning.

Williamson, Daniel. 2020. "Saying Goodbye to CNX and Hello to the Next Chapter!" February 7. Available at https://openstax.org/blog/saying-goodbye-cnx. 